\title{
Development of human consciousness
}

Colwyn Trevarthen ${ }^{1}$ and Jonathan Delafield-Butt ${ }^{2}$

${ }^{1}$ School of Philosophy, Psychology and Language Sciences,

University of Edinburgh

Dugald Stewart Building, 3 Charles Street, Edinburgh EH8 9AD, Scotland, UK

E-mail: c.trevarthen@ed.ac.uk

Web page: http://www.pmarc.ed.ac.uk/people/colwyntrevarthen.html

${ }^{2}$ Faculty of Humanities and Social Science,

University of Strathclyde

Lord Hope Building, St. James' Road, Glasgow G4 0LT, Scotland UK

E-mail: jonathan.delafield-butt@,strath.ac.uk

Web page: http://www.strath.ac.uk/staff/delafieldbuttjonathandr/ 


\section{Introduction: A natural science of awareness}

Biology of human awareness, and how it acquires consciousness of a cultural world

Recent research that uses refined methods of tracing infant's movements to determine how they are coordinated and integrated proves they are directed in selective ways to take in and adjust to information from the senses about the present environment. It shows that the circumstances and objects of the infant's actions are evaluated by the infant as 'good' (attractive and rewarding or pleasurable), or 'bad' (frightening and avoided, or resisted). The manifestations of purposeful, expectant and evaluated consciousness are identified as proof of Self-awareness, or 'subjectivity'. Studies of the imitative and provocative actions of newborn infants in response to the behaviours of other persons who give close attention to them prove also that there is an innate Other-awareness, or 'inter-subjectivity', that attends to and sympathises with expressive movements of a person (Trevarthen, 2001; Kugiumutzakis and Trevarthen, 2015).

We take 'awareness' to mean the ability of an animal subject to guide movements 'prospectively' to sustain a coherent Self in its world (Llinàs, 2001; Merker, 2013). Animal movement, unlike physical motion of lifeless matter, evolved to be self-created and self-related. Control of actions of a body in time and space, so that the life of the actor is directed to necessities of life or avoidance of harm, is essential for survival and development. Awareness, what is sensed and attended to, must be evaluated and elaborated with 'feelings' that protect well-being of the active self (Damasio, 2010), and these, for social cooperation in activities, are communicated as 'emotions', which shape the development of relationships and shared awareness.

In a discussion of the mind-brain problem, neuroscientist Roger Sperry (19131994) in 1952 made clear that we learn about a creature's mind by studying the 'output' of their life activity in movement, not by measuring or classifying available sensory 'input' and speculating how they might think about it or process it. 'Integration of information' is part of the process of an individual being conscious 'in the moment', ready to act. It is created to assist the impulse to move in a 'circular reaction' between the initiation of muscle action and sensory feedback, as described by James Mark Baldwin (1861-1934). The initial purpose or function of awareness focuses on what the environment affords for adaptive action in the future as proposed 
by James Gibson (1904-1979), and that is able to communicate this imagination for movement to other individuals with the emotional expressions illustrated by Charles Darwin (1809-1882). Input to the senses must be actively 'perceived', 'taken up' in a selective manner, and developed with intention.

Consciousness begins as a part of imagined 'projects' for moving intentionally from the present moment step by step in measured time. This term 'project' holds to its original Latin sense -- as an imaginative activity, a "throwing forward of movement for realization of a purpose". It is not only the abstract or symbolic representations of such intended action, in speech, writing, graphical plan or diagram, though these conventions of communication have their practical purpose in implementing projects. We are finding the foundations of a natural science of conscious human agency in infancy, when intentions and feelings and their evolution in life of an individual child are created intuitively and communicated directly to sympathetic others, without words, to develop cooperative agency and experience. We do not believe any formulated meaning of the word can make sense without accepting the primary impulse to act with anticipation of the consequences.

Margaret Donaldson (1992, p. 267) calls this the 'line mode' of human mental life, "concerned with events that have happened in the past or that might happen in the future: that is, with the 'there and then' ". This extending of interest and expectation is alive in any activity of awareness, even scientific speculation about the interneuronal processes that might structure a conscious experience. Experience taken up by an act of consciousness can be retained in memory, and it is 'remembered' as knowledge for future reference in real or imagined motor projects. By accepting, with Baldwin, the primacy of 'intentions to move' for locating and elaborating what the senses choose to receive, we avoid restricting 'consciousness' to mean only reflective, rational and verbally mediated processing of information that has been learned and stored in memory. Thus, we are free to observe human consciousness at its developmental origin and in patterns of movements that manifest the awareness of an infant (Trevarthen \& Reddy in press).

Human awareness shares basic features of animation in behaviors with other animals, including rhythmical timing and selective attention with affective appraisal. It also exhibits unique powers for the development and use of acquired consciousness of the world. It is specially equipped to share knowledge with other human beings in a 
community in order to develop traditional ways to sustain understanding of artificial cultural beliefs and practices, which receive elaborate definition and authority in language. Infant behavior, though it lacks such knowledge of this world and its representation in language, shows intelligent adaptations for learning and valuing meanings with other persons from the start of life in a family (Brazelton, in Bullowa, 1979, pp. 79-88). It is adapted for mastery of the special forms of semiosis, signalling in body movement for conversation about ideas with companions (Trevarthen, 2015).

Studying infants' awareness, and the development of meaning in common sense A key discovery has been that infants, besides promoting and regulating conscious actions of their subjective Self, are also, from birth and before, sensitive to and capable of engaging with the manifestations of consciousness with feelings in the movements of other human beings (Trevarthen, in Bullowa, 1979, pp. 321-347). We describe the earliest manifestations of this 'inter-subjectivity' in shared time and space, and how it develops in collaboration with sympathetic awareness of companions, first with the child's mother, but quickly becoming receptive to sympathetic attentions of other intimate acquaintances. In affectionate attachments with partners of all ages, conscious activities are shared and grow.

\section{Finding answers by avoiding disbelief}

A new beginning for a science of human nature and its intelligence

A child psychobiology that attends to natural patterns of movement for evidence of their guidance by selective prospective awareness of present circumstances and events, rather than to abstract rational explanations of conscious behavior for individual thinkers, accepts that the newborn infant is a conscious person, a being able to act with intentions that coordinate the parts of a complex body with many senses, and who possesses emotions for guiding a life of learning and development in dynamic human ways (Stern, 2010; Trevarthen \& Reddy,in press). Special abilities attract and guide carers who not only support and protect essential life needs, but who find joy in play with the meaning and feelings of the infant's actions and humors, their ability to 'know minds' (Reddy, 2008). They develop co-consciousness in sympathetic companionship. The child is, from the start, an active collaborator in this 
process of teaching and learning, a person seeking 'common sense' in life by acquiring efficient practices in engagements both with objects, and with other persons as animated beings who need to share awareness (Fig. 1).

Figure 1 about here

Repeatedly, the psychology of childhood, and the science of education for all ages, have had to revise their assumptions and practices by recognizing that they are inclined to neglect the child's initiative in doing, knowing and sharing of actionswith-awareness. We may cite the history of educational reformers recounted by Robert Herbert Quick (1831-1891) in 1890. As Quick showed, Rabelais, Comenius, Rousseau, Pestalozzi, Froebel and their like have all, with their successors Alfred North Whitehead (1861-1947) and John Dewey (1859-1952), celebrated the child's curiosity, sociability and 'zest for learning'. The importance of mastery by the infant of the complex human body in its movements was demonstrated in the 1940s by Myrtle MacGraw (1899-1988), a follower of Dewey's belief in the child's animation of his or her education by impulses for activity.

In this entry, we draw on contributions from brain science that confirm the existence of basic motor functions of embodied awareness in individuals, and of inter-subjective consciousness in their collaborations. More detailed neuroembryology of perception, the generation of motives for movements in space and time with 'affective consciousness', and how consciousness may be distributed, activated and integrated in brain circuits as they grow and mature in mastery of the motor and sensory organs of the body, are available elsewhere (Panksepp \& Trevarthen, in Malloch \& Trevarthen, 2009, pp. 105-146; Trevarthen et al., 2006; Trevarthen \& Panksepp,in press). A valuable commentary for understanding of individual volition and its awareness is provided by the philosopher Barbara Goodrich, who insists that brain science must confront the facts of phenomenal awareness in the rhythm of life activity. It cannot be just “... self-reflective, passive, and timeless" (Goodrich, 2010, p. 331), as the theory of contemporary cognitive neuroscience tends to be. She cites the exceptional contributions of neuroscientists Rodolfo Llinás and György Buzsáki who have attended to the processes of the whole brain that give rhythmical coherence to actions of the Self, and their attention to sensory experience. In line with this train of thought, consider the following: 
Eminent scientists have opposed the repeated reduction of brain function to hypothetical cognitive or input processes in mechanisms for perception and learning. By studying the anatomy and physiology of nerve tissues and their growth, they have established that the brain is shaped primarily for its output in body movement (Charles Sherrington; Nikolai Bernstein; Roger Sperry; Antonio Damasio). Research is making it ever clearer that our fundamental emotional structures engender dynamic patterned actions as well as motivation and feelings (Panksepp \& Biven, 2012). The function of the brain is to make the body engage the environment by moving its muscles in coherent ways with refined economy of the physical and chemical energies required to sustain mental balance. Good living moves harmoniously with wonderful efficiency and with playful good humour. Illness and distress cause weak or impulsive actions that meet the environment erratically and cause inner pathologies and conflict in communication. (Trevarthen \& Panksepp, in press to be published this year).

Infant consciousness exhibits core components of the vital intelligence of adult consciousness. Infants and their parents share a human body with the same basic measures of vitality in the prospective time of movement (Stern, 2010; Trevarthen, 2016). They express and engage one another with the same emotions (Trevarthen, 2009). The growing brain and body of the child will animate years of learning with a curiosity and affective consciousness that anticipates a knowledge of the world and its cultural interpretation. Even before birth, a baby can find fellowship in synchrony and sympathy with expressions of fully developed adult consciousness, provided that expressions of this more experienced awareness are modulated to enhance correspondence of motives and feelings between them, as in case of 'baby talk' with its conspicuous ‘musicality’ (Malloch \& Trevarthen, 2009). 


\section{brought to light}

The Royal College of Gynaecologists and Obstetricians, who have legal authority over the quality of medical care of young babies, published new guidelines in 2010 establishing that the fetus at 24 weeks gestation is a sensitive human being due the same standard of medical care as an adult, including analgesics to reduce pain. There is now evidence that human emotions of pleasure and pain are expressed by the fetus by gestures of the hands and expressions of the face (Reissland \& Kisilevsky, 2015). At 22 weeks gestational age, hand movements directed to touch the fetus's own mouth or eye, or to touch the uterine wall, have coherent self-related intentional form, timing and sensitivity (Zoia, Blason, D'Ottavio, et al., 2007; Delafield-Butt \& Gangopadhyay, 2013). In the period between 14 and 22 weeks gestational age, there is development of sensitivity to distinguish the body of the self from the body of a twin other, and, as the psychiatrist Alessandra Piontelli (1992) has shown, twin fetuses display differences of temperament, which persist through childhood.

Western philosophy, trained to use sophisticated rational ways of explaining conscious actions and their recollection in thoughtful debate and text, has long struggled with the notion of a primal awareness of movement regulated by an integrated self-consciousness. This tradition has led to the theory that consciousness is 'constructed' in infancy by learning how to integrate supposedly mindless reflex sensory-motor responses in intelligent projects, and development of a 'theory of mind'.

In recent decades, a child psychology that accepts Darwin's theory of evolution by natural selection of adaptive use of experience, has found a different origin for human consciousness. Primary features of control and evaluation are active in an infant's movements from birth, and they have temporal features and affective modulations matching those intuitively governing activities and communication of an affectionate parent. Comparison with other species, including apes, throws light on the special adaptations of social signalling in infants and parents for motivating development of human cultural awareness mediated by symbols (Llinàs, 2001).

\section{What is consciousness? How are we conscious?}

There are important distinctions to be made in how we use language. Does 
consciousness mean 'Acting with knowledge', the $H O W$, or is it just the object, 'WHAT we are knowing'? Is it observable in behavior of other individuals just like any other environmental event, or must it take into account inarticulate feelings that affect what they and we attend to with a living volition? Reflective or discursive consciousness is what philosophers argue about, and many are persuaded that animals and newborn infants are unconscious beings, but new resurgence of interest in the phenomenological tradition of 'Continenatal philosophy' of the $19^{\text {th }}$ and $20^{\text {th }}$ centuries recognizes the foundation of consciousness as pre-reflective, pre-conceptual, and grounded in the rhythms of a body acting with a sensorimotor intentionality (Delafield-Butt \& Gangopadhyay, 2013). Jaak Panksepp, a leader in research on the emotions of animals, shows that neuroscience, too, has been distracted by selected facts of neural activity, which are assumed to exhibit, and depend upon, 'processing' of sensory information (Panksepp \& Biven, 2012).

Accounts of the experience of creative consciousness include reference to aggregations of actions and feelings that constitute it through the time of intentional activity. That is what Mozart described, in a famous letter, about how music came to him as a gifted young practitioner of the performance and invention of the art.

If consciousness is an act of living discovery, of experience created by a whole person as an agent with alert body and mind, intentions, sensations and feelings, it must be explained by consideration of the nature of the human organism's life story. It involves how the mind comes to be, what its motivations and feelings are from the beginning, and how it is sustained.

Finally, to understand the transmission of human knowledge, we have to consider how the impulses of consciousness are shared in a community. A vivid part of our life is an immediate awareness of the presence of other persons with appreciation of their self-related attitudes and expressions. We enter the will and feelings of other persons simply by perceiving the expectations and evaluations of what they are doing with their movements from infancy (Kugiumutzakis \& Trevarthen, 2015; Reddy, 2008).

\section{Knowing with purpose and feeling, and its sharing in company}


An animal's consciousness is organized with reference to the form of its body and potential movements, which direct sensory organs in selective perception of the environment that constitutes that species' Umwelt or 'life world' of the biologist Jakob von Uexküll (1854-1944). The experience of all of its many parts must become an 'imaginative project' of the self-as-agent integrated by the central nervous system. Furthermore, the conscious experience of a single self-as-agent who is about to act requires the attribution of vital, affective value or 'feelings' to every object it is interested in (Damásio, 2010). This 'affective appraisal', as Sherrington had called it, gives special importance to every decision or event that is experienced by the Self .

The appreciation of the 'affordances' of material objects or social partners, what can be done with them by the actions of the coordinated self, is mediated by ancient midline networks of the brain stem and midbrain, which are highly conserved across vertebrate species (Merker, 2013). Core affective consciousness carries a deep phylogenetic history, which our conscious experience shares with that of other species (Panksepp \& Biven, 2012). These integrative mechanisms of the physiology of body and brain, and their adaptation for communication in movements of cooperative social life are much elaborated in human beings and animated in all forms of music (Malloch \& Trevarthen, 2009). They mediate our mental health, and its celebration in the arts.

Feelings generated within sub-cortical structures that integrate action-withawareness of the whole body with its separately mobile parts, not only evaluate the sensations appreciated by the body in the present moment for immediate benefit or protection, they build experience of agency through time to create episodes in life stories of the Self (Trevarthen \& Delafield-Butt, 2013). Projects of purposeful, ordered movements, planned to accommodate their future effects, are first evident in proprioceptive regulation of movement patterns of the fetus, which test body awareness (Delafield-Butt \& Gangopadhyay, 2013). After birth, with discovery of 'distance senses', especially vision, intentional movements direct infant consciousness in more adventurous ways, assimilating perceptions of the world outside the body (Delafield-Butt \& Trevarthen, 2015). This is the growth of what Margaret Donaldson calls 'human sense', beyond the infant's 'point' mode of mind, with a 'locus of concern', in the 'here and now'. With increasing scope of imagination and memory, new powers of body movement and more discriminating perception of 
features in the world, a 'line' mode comes to life that casts the awareness of significant past into the possible future. This mode predicts what will happen when the mind conceives of doing something, 'anytime and anyplace'. According to Donaldson:

The devising of novel purposes comes readily to us because we have brains that are good at thinking of possible future states - at considering not merely what is but what might be. We exist in a world of 'hard fact', but we can imagine it as changed; and from a very early age we know that, within certain limits, we are able to change it. It matters very much to us to find out how these limits are set, an activity closely related to the general purpose of understanding what the world is like. In this context 'the world' includes other people as a most important component. And, if we have any wisdom, it also includes ourselves (Donaldson, 1992, p. 9).

With maturity awareness of phenomena and their meanings becomes abstract or 'transcendent', out of space and time', and Donaldson distinguishes this selfgenerated kind of understanding as 'intellectual', as in science and mathematics, and 'value sensing', as in arts and religion. In old age, as powers of action weaken and ambitions decline, we again attend more to inner processes of thinking and feeling, as we did in infancy.

\section{Consciousness without emotions cannot communicate}

As Darwin discovered, emotional expressions serve as agents of selection for survival in the evolution and development of all animals, from bacteria or insects, to octopuses, fish, birds and mammals (Packard \& Delafield-Butt, 2014). Emotions evaluate what the world has to offer in relation to the needs of the self for sustenance, play, courtship, and safety. Infant consciousness is richly expressive of emotions with intentions, and it communicates with these affective states of mind as they regulate awareness in other persons.

Adult feelings are powerfully affected by sensitivity for a baby's smiles and coos or grimaces and cries. Babies, for their part, require immediate reciprocal engagement with an adult's emotions to maintain their health, self-confidence and good humor in being. For example, in an experiment where the mother is asked to 
cease movement during the flow of a happy proto-conversation with her baby, the infant quickly becomes distressed and avoidant. The same happens if a portion of the mother's part in a live chat with her baby mediated by double television is replayed to the baby (Fig. 2) The insensitive replay betrays the baby's expectations and immediately causes him or her to become unhappy, distracted and avoidant (Trevarthen, 2009).

Figure 2 about here

Social connection in shared consciousness can be evident within minutes of birth. It is appreciated, with reciprocal imitation, by a multimodal awareness of movements of the head, face, hands and voice that communicate feelings with intention (Kugiumutzakis \& Trevarthen, 2015).

Sensori-motor regulation of awareness of the self in three domains of vitality

Sherrington (1906) defined three systems of the central nervous system (CNS) that take up and integrate sensory information of an animal agent. These are subjected to selective control by muscles that move the associated sense organs.

First is the visceroceptive 'world' within the body, regulated by the autonomic nervous system. Heart rate, blood pressure, blood oxygenation, metabolic activity, digestion, water retention, together contribute to maintain the physiological state and the search for vital needs of the individual, both in the present moment, and in preparation for future well-being.

Second, the proprioceptive system, including the stretch receptors, muscles spindles and the vestibular organs that detect physical effects caused by displacements of the body and its parts, measures forces inside the body-in-action as it regulates posture and gesture the gravitational field.

Third, detection of opportunities for action with awareness beyond the body is mediated by exteroceptive senses of touch, hearing, olfaction and vision. These confirm the location and displacement of the body in relation to the world by 'exproprioception', and identify objects and organisms, by the 'distance receptors' of sight, hearing, and smell, and by the proximal receptors of taste and touch.

Information about the whole integrated life-world of the Self is conceived from 
these three axes or windows of awareness to form a detailed account of the body as it moves through space and time, together with appreciation of resources vital for its needs for sustenance and safety, or the advantages and risks of social engagements with other selves (Fig. 1)

\section{Making of primary embodied consciousness before birth}

Intrinsic motives for an aware life from the first movements

After 'autopoesis' or self-making of the embryo body shaped for purposeful forward directed motor activities, and mapping of this body form in the ectoderm tissue of a primordial CNS, the inter-cellular systems for regulating awareness with emotion become integrated during the first month of gestation, fashioning an 'intrinsic motive formation' (IMF) which is elaborated in later stages (Trevarthen, 2001). This foundation for conscious activity shows functional mapping among groups of cells in the CNS before its network is electrically active, and before neurons of the cerebral cortex are generated in the forebrain.

The IMF comprises a chain of special visceral motor nuclei of the hind brain that are formed primitively to activate autonomic functions, and that become specially adapted in the human fetus for future participation in 'conversations of feeling', by head and eye movements, face expressions, vocalizations and gestures. By the end of the second month, the beginning of the fetal period, the main components of the brain are in place and the special sense organs of the head, face and hands are being given their dedicated form for sight, hearing, vestibular sense, olfaction and touch, as well as for their participation in intimate communication (Fig. 3). All are impressed with a 'somatotopic code', which coordinates their connections after axons grow to link the different areas.

Figure 3 about here

\section{Beginnings of human sense in the sub-cortical brain}

The neuroscientists Jaak Panksepp and Bjorn Merker explain conscious experience as the product of an ecological system of the animal active in its environment, with awareness regulated by affective evaluation within the upper brain stem (Merker, 
2013; Panksepp \& Biven, 2012;). Anencephalic or hydranencephalic children, who do not possess cerebral cortices but have intact brain stems, can live for some time postnatally, orienting attention to events outside them, showing emotions of pleasure and distress in social encounters generated in 'core affective systems'. Although their cognitive capacities are greatly reduced, these children are manifestly conscious, have feelings, and shape their actions with intention. Following development of the foundations of these mental functions in the early fetus, a human infant is prepared for cultural or collaborative learning in affectionate relationships from birth.

\section{The appearance of a conscious rhythm of intentions}

First movements made spontaneously by a human fetus at 2 months have controlled timing and sequencing. They are neither random nor reflex responses. They are 'intentional' or 'aware', showing anticipation of sensory confirmation for various self-related effects (Delafield-Butt \& Gangopadhyay, 2013). Ultrasound recordings of the spontaneous movements of an undisturbed, second trimester fetus within the uterus show the hands making careful exploration of the body, head and face, and expressions by the face of delight or disgust in discriminating response to substances encountered in the mother's body. These movements occur before the cerebral hemispheres are functioning, and are clearly adapted for the intimate communication of states of consciousness with feeling. Researchers have also found that the touching movements fetuses direct to their own body are different in their dynamics from those reaching out to touch the body of a twin. The latter gesture is slower or more 'careful', demonstrating a respectful sensitivity for the other self, or 'social awareness'. There is an intimate transmission of states of vitality in movement between mother and fetus. Nadja Reissland has found that after 20 weeks, fetuses may make gestures of self-touching with the left hand that appear to signal emotional attitudes in sympathy with a mother's feelings of stress. They show positive response, such as smiling, to her voice, and they may shape mouth movements of articulation when hearing a person speaking. They also show distress when subjected to intoxication by a mother's smoking (Reissland \& Kisilevsky, 2015).

The new findings in fetal psychology confirm that the core structure of 
consciousness with feelings is active before the neocortex is functional and before postnatal experience of the world, and that it has features that remain invariant throughout cognitive development. It grows from a primary, brain stem mediated consciousness, with intentional action, perceptual awareness and affective appraisal, and the expressive prosody and syntax of its movements are adapted to gain a reflective, conceptually backed abstract consciousness that can be represented in the semantics of language. Human socially negotiated or cultural consciousness, developing symbolic communication of conventional ideas, rituals, and techniques, depends on the organs for communication of impulses of consciousness, by movements of facial expression, gesture and vocalization, with their associate capacities for sensory confirmation and perceptual discrimination. These organs develop their functions from the last trimester of prenatal life.

How the motives and feelings are transferred between the embodied minds remains a mystery for a psychology that does not have sufficient information about the motive states that 'programme' integrated body movements through time. The consequence is that they may construct intentional projects and give narratives about them (Bruner, 1990; Delafield-Butt \& Trevarthen, 2015).

\section{Readiness for shared primary consciousness}

In response to the last question concerning the origin of human interpersonal affective and intentional consciousness and how it develops in the fetus anticipating dialogue, we present an account of the actions-with-awareness-and-emotions of a two-month preterm newborn, around 32 weeks gestational age, in intimate communication with her father. A sensitive exchange of short vocalizations between the baby and the father, who was holding his daughter under his clothes against his chest, reveals that they shared the same sense of time for alternation of syllables and phrases in a conversation without words.

Naseera was born 3 months preterm in an Intensive Care Unit where intimate body-to-body contact by 'kangarooing' was being used by the pediatrician Richard de Leeuw to help the physical and mental development of very preterm babies, and to support and encourage the confidence of their parents. Her mother began attending to Naseera, but soon had to be taken from her to have a surgical operation. Her father 
took over the kangarooing, and with pleasure and pride accepted Naseera to his body under his clothes every day, cradling her against his skin and responding to her movements and expressions with gentle touching and speech.

The development of their intimate relationship, and Naseera's excellent progress with her father's sensitive care was documented by videos made by a clinical psychologist Saskia van Rees. Figure 3 shows her vocal responses to imitations of her father at two months before term, one month after her birth.

\section{Transformation of awareness after birth}

Neonatal imitative dialogues and development of proto-conversation as narratives of life in relations

Full-term newborn infants show immediate awareness of objects outside their body, and they can imitate deliberate movements of head, eyes, face, voice and hands, and repeat them to sustain a dialogue, displaying a social consciousness with emotional sensibility that is very appealing for a parent (Trevarthen \& Reddy,in press). The dynamical properties of Naseera's movements, reveal a sense of time and feelings of affection that correspond with adult actions and feelings (Trevarthen, 2016). They have narrative form revealing that the vitality of experience passes through measured phases (Delafield-Butt \& Trevarthen, 2015). How?

Within a few weeks, this 'thinking in movement' can excite a parent to appreciate and share the infant's 'story' with astonished pleasure, in 'protoconversation' (Bateson, in Bullowa, 1979, pp. 63-77; see Fig. 5). Thus begins intuitive support for the life of the primate Homo sapiens, sharing a unique, speciescharacteristic, capacity for the 'make believe' of cultural consciousness, which will lead to symbolic play, speech and language, and a heritage of rituals, artistic productions, beliefs, built environments, and science.

Figure 5 here

Development of cultural consciousness before speech: Secondary consciousness

The human consciousness beginning in the mid-term fetus undergoes age-related transformations through the whole life of that person. Learning is subject to 
developments in motives that change the life of the body and the functions of the brain. Changes are particularly rapid and transformative in infancy and early childhood as first cultural habits are mastered. Key stages in the first 18 months after birth are summarized in Table 1 (Trevarthen, 2015).

Table 1 about here

The first two months may be seen as a maturation of adaptations for simple acts that orient actions directed to detect features of the immediately present outside world, and for a primary engagement with purposes and feelings of a caregiving adult. In the third and fourth months, both these forms of consciousness are transformed. As binocular vision matures and the support of the head and reaching of the arms become stronger, the baby shows more discriminating awareness of objects distant from the body. Attention to the mother for intimate face-to-face communication is reduced as the baby becomes more playful and provocative (Reddy, 2008; see Fig. 6). This incites an affectionate parent to present teasing games and ritualized performances in the form of nursery rhymes and body-action games. The infant finds these very attractive and learns the conventions quickly (Malloch \& Trevarthen, 2009). The growth of consciousness is led by selective attention to support curiosity in directing of movements and learning of skills.

Figure 6 about here

'Play' is identified as one of the principle emotional systems of the brain stem system, showing deep evolutionary roots across the vertebrates (Panksepp \& Biven, 2012). Studies of play in infants and children demonstrate its importance for learning and development of conscious knowledge, animating a space to master intentions enacted through movements, and to learn the joy of success and to remember the frustration of failure. Made with others, play becomes an important mediator for social understanding, enabling the intentions to be shared and learned, affiliative bonding, and social understanding within a community (Reddy, 2008). Playful impulses of imagination in moving motivate high achievements in art and science. Einstein confirmed that enjoyable imagination of body movements inspired his mathematical invention.

Meaningful cooperative communication before talk: Performing a personality 
By the end of the first year, self-consciously performed and shared games with marked 'second person awareness' (Reddy, 2008) lead to cooperative activities that involve sharing intentions for the use of objects as tools for tasks, such as eating food, carrying small objects in containers, or using furniture or transportation devices to support the body.

Two-month-olds, when they are lying flat on their back on a pad that records their body movements, are found to change the tonus of their body in preparation for being lifted when a parent leans over them to pick them up. This shows a readiness for sharing intentions (Trevarthen \& Reddy, 2016, in press). One-year-old infants cooperate in giving and taking objects and follow pointing gestures (see Fig. 7). They are extending their awareness of other's intentions to include their selective attentions and instrumental actions.

Figure 7 about here

As was observed by Henri Wallon (1879-1962) in the 1940s, a young child's self-awareness accompanies an awareness of being appreciated by others This leads to displays of what he called posturing or 'préstance'. Imitation and pretence build a strong sense of social self to be shared with companions of any age in imaginative games and stories.

\section{Consciousness growing after learning to walk and talk}

By the middle of the second year, the period of infancy ends when non-verbal 'protolanguage' becomes language (Halliday, in Bullowa, 1979, pp. 171-190). Most children at this age are comprehending words that others use to name objects and actions that are shared intimately. Imaginative play with increasing curiosity for others' intentions leads to cultural learning in the full sense, and it involves strong feelings of self-conscious pride and fear of shame (Reddy, 2008; Trevarthen, 2009). The child is beginning to walk, which greatly expands their world they can apprehend and the range of acts of communication. Two-year-olds, while becoming much more aware of the manners and interests of their family, are famously wilful and determined to regulate their own experience. Their expanding abilities allow them to share play with peers and other children, exploring inventions of a bigger makebelieve world (Bruner, 1990; Donaldson, 1992). 


\section{Motivation for human consciousness: A summary of the developmental process}

From the start, human consciousness is adapted for a lifetime of learning in companionship

In all stages of the development of a child's intelligence, from the subtle awareness manifest in infancy to the self-confidence of the toddler in the community and development of fluency in language, invariant principles of self-generated intentional movement are shared. These show sympathetic imagination and affective evaluation to motivate learning in companionship (Delafield-Butt \& Trevarthen, 2015). The impulses of the child need response, and can be formalized to guide educational practice. With others' help, the learner builds a purposeful sense of the future that enhances the vitality of the individual, and the life of the family and community. Conscious awareness expands and refines its aesthetic and moral feelings with abstract thoughts and plans that can imagine objects and events outside the present moment, and in conventional ways.

Jerome Bruner, in the 1960s, described progress of the child's initiatives in consciousness from enactive or action-based, to iconic, image-based, and then to language-based symbolic representation. This series compares with Donaldson's account of the child's growing 'locus of concern', from the infant's point mode of immediate experience in action, to the line mode of cognition through time and in different circumstances, and then to construct and transcendent modes of representation (Donaldson, 1992). It also recalls the description by the philosopher Whitehead of a child's development and learning passing through phases of romance, discipline and generalization. It is clear these leaders in the humanist theory of education, while agreeing that the child has creative initiative from the start, place differing emphasis on the intentional and emotional aspects of the child's endeavor. All accept, with Lev Semyonovich Vygotsky (1896-1934), that a curiosity about meanings to be shared is in the nature of the child, and is essential for the cultivation of cultural intelligence. In his consideration of the psychosocial development feelings of a child with experience of life in the family and community, the developmental psychologist Erik Erikson (1902-1994) adapted psychoanalytical theory to explain normal creative development of the feelings of the child's person in emotional relations, and emotional responses to unsympathetic support. He described these four 
phases from infancy to maturity: trust vs mistrust, autonomy vs shame and doubt, initiative vs guilt, and industry vs inferiority.

Following discoveries concerning the foundations of affective values for intentional action that develop in the sub-cortical parts of the mammalian brain before birth (Merker, 2013; Panksepp \& Biven, 2012), and reflecting on the more sensitive interpretations of how the child participates in and contributes to aesthetic and moral evaluations of human collaboration in life, we identify three early phases in formation of cultural awareness in the mind (see Fig. 8). These map foundations for a lifetime of consciousness and its stories, as follows:

Primary consciousness develops in embryogenesis and is first operative in early fetal life, mediated with the appearance of the brain stem Intrinsic Motive Formation (IMF) (Trevarthen, 2001). Core regulatory mechanisms, the peri-aqueductal grey of the midbrain, the hypothalamus, reticular formation, basal ganglia and limbic system, are laid down in the first trimester. They organize sensory regulation of movements of the body and limbs of the fetus in patterns that gain affective evaluation and sensitivity for sounds and rhythms of other human presence. Purposeful action, rudimentary learning and memory are evident, but the cognitive systems of the cerebral cortex do not appear until the second trimester. They develop massively after birth.

Fetal cognition is embodied and enactive, regulated by sensations generated in the moving body, and by sensory contingences of contacts with the immediate, tangible environment. Emotions that will regulate communication in later life are portrayed in face expressions and gestures. Primary consciousness becomes evident in purposeful movement of the foetus at the end of the first trimester, is active at birth, and remains across a lifetime, gaining additional powers of memory and imagination.

Secondary consciousness begins with development of limbic function of the forebrain in the last trimester of fetal life and in early infancy. It enables a fetus to develop coordination of intentional actions that intend to reach goals outside the body. After birth, it is ready to animate plans for serial ordering of actions allowing them to be imagined beyond the 
present moment. Intrinsic rhythms and intensities of neural activity regulating the dynamics of movement engage with matching impulses of a parent's affectionate expressions in proto-conversational dialogues of 'primary intersubjectivity' (Table 1, months 1 and 2). These abilities are active before visual awareness and interest in the environment more distant from the body undergo rapid development in the middle of the first year of postnatal life (Table 1, months 3 to 9). The fundamental mechanisms for vocal expression of emotion, and those for articulation of speech that develop later in the cerebral neocortex, are organized around mid-gestation in nuclei of the brain stem, with the basal ganglia, thalamus and limbic cortex. Multimodal afference for brain stem circuits would seem to be crucial to communication with neonates and for their first imitations, which develop into well-controlled protoconversational abilities by 6 weeks. An enactive and embodied cognition modulates the primary intentions to begin learning about the outside world, and to share experiences playfully. A store of memories of events begins to extend awareness of possible futures, which are discovered in the present moment in the rhythmic harmony of movement in the body, and communicated with other persons in the shared narrative forms of affect and intention of 'communicative musicality'. Tertiary consciousness develops through later infancy and early childhood as new neocortical functions bring a more discriminating awareness and more extensive imagination to direct growing motor skills. Learning abstract, reflective, conceptually-backed plans enables intentions-to-act to be retained for hours, days, or more. This 'off-line' reasoning, with added thalamo-cortical systems of awareness, continues to rely upon the initiatives and affective evaluations of limbic and brain stem systems, and is structured in space and time by their body-related vitality dynamics. In the second year, development of the cooperative awareness of 'secondary intersubjectivity' marks the beginning of a personal and technical education for mastery of manners and skills of cultural life in a community beyond the family, but is dependent upon the impulses and feelings active in earlier stages (Trevarthen, 2001). 
Figure 8 about here

Developments in the meso-limbic cortices of the temporal and frontal lobes in infants and toddlers transform autonomic self-regulation, the expressions of emotions in communication, and the motives for action and experience. At all stages, these later maturing limbic and neocortical circuits, with growth of the cerebellum, emerge in reciprocal, dynamic and increasing involvement with the multi-modal core regulatory systems of the IMF that were formed in utero.

\section{Maturation of tertiary consciousness for future learning}

As the toddler grows new powers of rapid movement, especially of the hands and vocal organs, timed and sequenced with increasing precision by the Selfsensing cerebellum, culture shapes consciousness with symbolic communication of meanings in language. The capacity of neocortical and limbic systems is expanded to learn and retain knowledge of specific objects, events, and concepts, and to evaluate them with recognized aesthetic and moral feelings. Through ritualized instruction or teaching, this growth is 'cultivated' and the values and procedures of a community learned according to a planned curriculum. But natural expansion of knowledge with affective and perceptual discrimination, reflection and reasoning, depends on active emotional engagement of the will of the child with social others, in affectionate and playful cooperation.

\section{Conclusions}

Human Self-awareness is generated within an active and perceptive body from early fetal stages, and develops after birth in experience with affective appraisal and in intimate communication of purposeful experience with familiar companions. The special powers of cultural consciousness that grow from infancy can be understood in light of new information on life functions that develop before birth. This constitutes an organic theory of consciousness, evolved to develop intersubjective intelligence that communicates awareness of cultural meanings. 
Consciousness as 'acting with knowledge' requires a nervous system that regulates prospective perception in intentional engagement with the world. The neural systems that integrate internal sensory information for the whole body develop in the embryo during the first eight weeks of gestation. They integrate sensory information in coordination with the impulses of a motor system and are capable of selecting and structuring perceptual experience in the time of self-generated, goal-directed action. By fourteen weeks, the fetus demonstrates prospective awareness and intentional motor control of a 'primary human consciousness'.

The joyful and exuberantly social consciousness of a young child is adapted to share growth of the experience implicit in the form and style of agile body movement. From birth, rhythms of movement with gestures that display our affective, vital states of well-being or distress are shared in emotional attachment with caregivers. These enable exercise of a 'secondary consciousness' in 'primary intersubjectivity', which directly perceives both the affordances for action in the material world and of collaborative awareness with the mental states of others, without mediation by abstract, reflective thought.

As perceptual discrimination improves with growing postural and motor control, a child's playful engagements with objects and other persons take on longer durations, increasing the range of prospective planning with affective appreciation, and enriching a story of memories. Acquired meanings are held, not as a collection of discrete and timeless facts, or simply as schemes for motor control of the sensorymotor Self, but as lived and embodied projects that unfold over time in active participation with emotional companions, creating the foundation of our narrative intelligence, which has its temporo-spatial, body-related, foundations in sub-cortical, stem parts of the brain (Delafield-Butt \& Trevarthen, 2015). With addition of cortical capacities for holding details of experience 'in mind', consciousness develops the abstract imagination with symbolic meaning of language and educated adult consciousness. Then conceptually backed plans for intentions-to-act rather than immediate intentions-in-action expand conscious experience to allow technical and cultural mastery in its tertiary form. Infant and child psychology shows is that the essential element, or core, of conscious awareness and intention with prospective engagement in human story-making is evident from very early life.

Brain science of the evolution and development of limbic and 'frontal 
executive' regions of the forebrain, and their reciprocal connections with brain stem motive, motor and affective systems, confirms this theory of the regulation of learning by motive impulses and emotions and their communication, supporting a richer understanding of needs for early child-centered educational practices, and the recognition and care of individuals with special abilities in the arts and sciences. There are also important implications for the recognition of disorders of consciousness and their causes in development. 'Mental illnesses', such as autism spectrum disorder, attention deficit hyperactivity disorder, schizophrenia, depression and dementia, are found to be associated with early disturbance of the sense of time in movement, and of emotions that protect the Self in action and in communication. These call for treatment by 'non-verbal' or motor therapies that are complementary to rational and verbal psychoanalysis (Stern, 2010). Further implications concern interpretation of genetic factors and their expression within epigenetic systems of morphogenesis in body and brain that regulate their expression. We need data to distinguish effects of adaptive 'environment-dependent' learning from the patterns of 'environment-expectant', and 'experience-seeking' processes that may grow in the brain, with affective regulations. An integrative approach to the early development of human awareness is required that seeks information from neuroscience in relation to the fine details of spontaneous expression of intentions and feelings, and how they may animate immediate sympathetic responses from caring companions, generating shared consciousness and the foundations for meaningful social understanding.

See also:

Constructivist theories; Learning theories; Dynamical systems approaches; Fetal ultrasonography; Prenatal neural development; Prenatal development of the musculoskeletal system in the human; Prenatal sensory development; Play; Status of the human newborn; Cognitive development during infancy; Memory and learning; Multisensory perception; Language acquisition; Social development; Emotional development; Play; Selfhood; Socialization; Theory of mind; Perception and action; Brain and behavioral development; Social neuroscience; Autism; Evidence of evolution in human development 


\section{Further reading}

Bråten, S. (2009). The intersubjective mirror in infant learning and evolution of speech. Amsterdam: John Benjamins.

Gallagher, S., \& Zahavi, D. (2012). The phenomenological mind (2 ${ }^{\text {nd }}$ ed.). Oxford, UK: Routledge.

Trevarthen, C. (2004). Brain development. In R.L. Gregory (Ed.) Oxford companion to the mind (2 ${ }^{\text {nd }}$ ed.) (pp. 116-127)._Oxford, UK: Oxford University Press

Trevarthen, C. (2004). Infancy, mind in. In, R.L. Gregory (Ed.) Oxford companion to the mind ( $2^{\text {nd }}$ ed.) (pp. 455-464). Oxford, New York: Oxford University Press.

Whitehead, A. N. (1926). Science and the modern world. Cambridge, UK: Cambridge University Press. 